\title{
Award-winning paper in 2014
}

Papers published in the International Journal of Physical Modelling in Geotechnics are eligible for awards from the Institution of Civil Engineers. Papers from any of the ICE journals can be nominated for several awards.

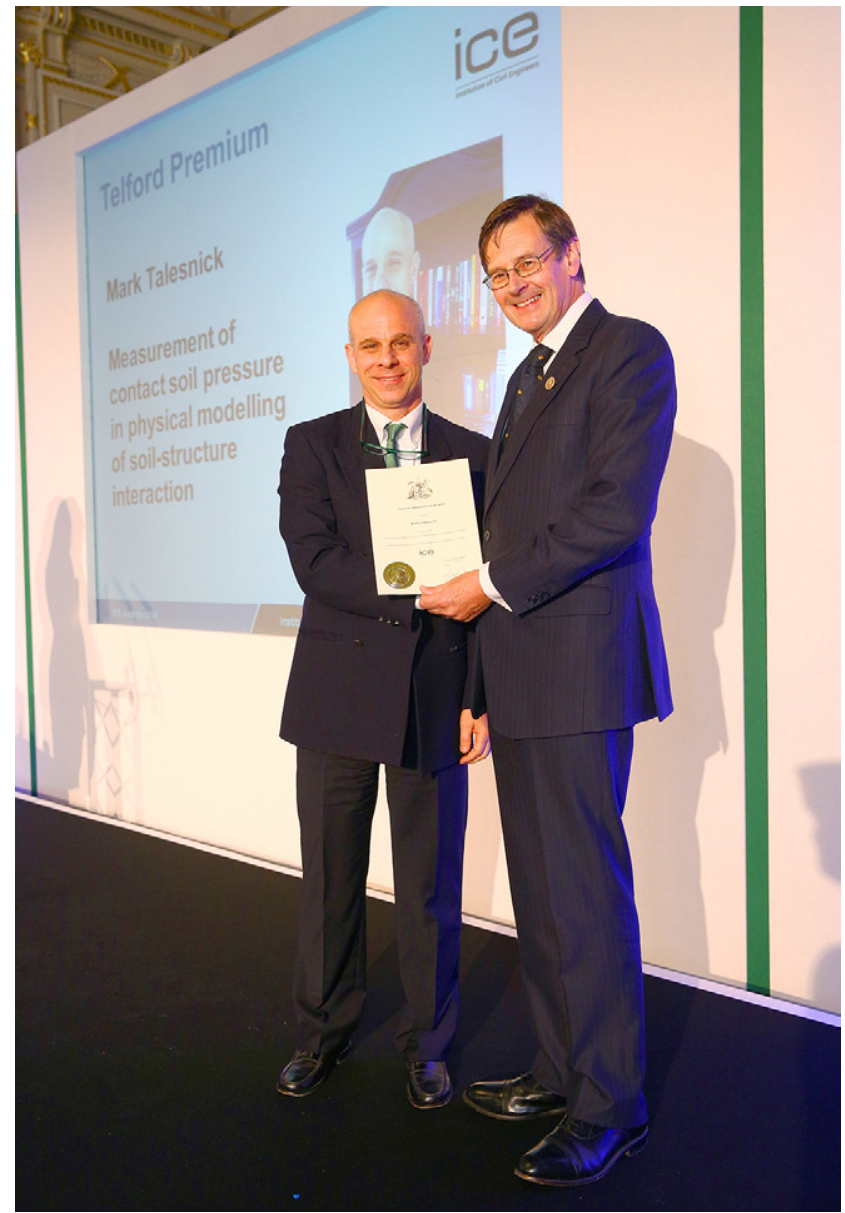

ICE President David Balmforth with Thomas Telford Premium Prize winner Mark Talesnick.
In addition, each journal has awards dedicated to their specific subject area.

On Friday 9 October 2015, ICE president David Balmforth presented awards to the following papers published in International Journal of Physical Modelling in Geotechnics in 2014. The editorial panel nominated their best papers and an awards committee chaired by Quentin Leiper allocated the awards.

\section{Thomas Telford Premium Prize}

The Thomas Telford Premium Prize was awarded to Talesnick et al. (2014)

\section{Abstract}

Meaningful measurement of contact soil pressure at the interface of a structural boundary has been a cause of frustration to experimentalists in the field of soil mechanics and soil-structure interaction. The difficulty stems from the fact that most sensing systems involve compliance, which induces a local redistribution of pressure in the soil mass. In effect, the attempt to monitor soil pressure ruins the measurement. The paper uses a concept called the 'null soil pressure system', which is an active sensing system requiring that the sensing element be continuously and stringently maintained in an un-deflected state. Results illustrate that the nulling pressure required to maintain the membrane in the un-deflected state is in a 1:1 ratio with the applied soil pressure, and is independent of soil type, particle size and particle arrangement. No hysteresis is noted between loading and unloading, and additional loading cycles align with that of the first loading cycle. Relevance of the system within the realm of physical modelling with/of granular soils is illustrated by considering: limitations on membrane deflection; limitations on sensor diameter relative to particle size; measurement of soil pressure on a structural interface while subjected to shear stress and relative shear displacement

\section{REFERENCE}

Talesnick ML, Ringel M and Avraham R (2014) Measurement of contact soil pressure in physical modelling of soil-structure interaction. International Journal of Physical Modelling in Geotechnics 14(1): 3-12. http://dx.doi.org/10.1680/ijpmg. 13.00008 